\title{
DESAFIOS DA FORMAÇÃO DOCENTE INICIAL E AS PRÁTICASS DE ESTUDO NA EDUCAÇÃO MATEMÁTICA ESCOLAR
}

Luiz Carlos PAIS

Universidade Federal do Mato Grosso do Sul lcpais@nin.ufms.br

Marilena BITTAR

Universidade Federal do Mato Grosso do Sul marilena@nin.ufms.br

José Luiz Magalhães de FREITAS ${ }^{1}$

Universidade Federal do Mato Grosso do Sul

iluiz@dmt.ufms.br

Resumo: O objetivo deste texto é descrever uma análise de alguns desafios atuais da formação de professores de Matemática para a Educação Básica e, mais especificamente, as práticas e os saberes característicos das culturas escolares e universitárias. Esta análise foi conduzida a partir do pressuposto que existe uma grande diferença entre as práticas cultivadas nos anos de estudos universitários, no contexto dos cursos de licenciatura, e aquelas que caracterizam as tarefas escolares da educação básica. Trata-se de uma tentativa de debater a expansão qualitativa da formação profissional docente cuja superação exige a articulação entre as culturas universitárias e escolares. De modo geral, esta questão não tem sido levantada nos cursos de licenciatura de Matemática e persiste velada, como se a natureza das práticas escolares quase nada tivesse em comum com os estudos universitários, a não ser a condicionante do domínio de conteúdos específicos. Assim, para desenvolver o objetivo proposto são destacados aspectos específicos da Matemática escolar, procurando não perder de vista o conjunto das disciplinas escolares. Trata-se de realçar aspectos metodológicos específicos do ensino da Matemática escolar em sintonia com a formação vivenciada nas instituições acadêmicas. O estudo dessa questão é conduzido com base na teoria da transposição didática e, mais amplamente, na abordagem antropológica do estudo escolar, proposta pelo educador matemático francês Yves Chevallard e compartilhada pelos seus parceiros pesquisadores. Uma análise de discurso foi realizada em um conjunto de unidades retiradas dos textos originais, as quais foram projetadas na realidade educacional brasileira. A realização deste estudo permitiu

\footnotetext{
${ }^{1}$ Professores e orientadores do Programa de Pós-Graduação em Educação Matemática da Universidade Federal do Mato Grosso do Sul.
} 
identificar a existência de uma distância considerável entre práticas docentes escolares e aquelas pertinentes aos saberes acadêmicos, abrindo uma espécie de vácuo entre os saberes escolares e as práticas vivenciadas nos cursos de formação docente. Uma das consequências desse problema é o predominio, no cotidiano escolar, de aspectos mais instrucionais do que educativos. Isso pode ser comprovado por meio da identificação de aspectos disciplinares e didáticos, onde as estratégias metodológicas são quase sempre confundidas com a formalização textual do saber matemático.

Palavras-chave: Formação docente. Práticas escolares. Educação matemática.

Abstract: The objective of this text is to describe the analysis of some current challenges to train Mathmatics teachers for the Basic Education and more specifically on what comes to practices and characteristic knowledge of school and university cultures. This analysis was done based on the assumption that there is a great difference between the practices developed along the years at the university, on the teaching graduation courses, and those practices which characterize the school tasks on the Basic Education. It is an attempt to discuss the quality development of the teachers professional formation. In order to surpass this formation it is necessary to articulate both the university and school culture. In a general way, such question has not been discussed on the Mathematical teaching graduation courses and still keeps covered, as if the nature of school practices had almost nothing in common with the university studies, but the conditioning domain of specifc contents requirement. Thus, in order to develop the objective proposed, we outstand specific aspects of School Mathematics trying not to set apart the other disciplines. It is a matter of outstanding specific methodological aspects in Mathematics teaching in accordance with the formation held in academy institutions. The study of such question is underpinned based on the Didactics Transposition Theory and in a more ample way on the anthropological approach of school classes, proposed by the french mathematician educator Yves Chevallard and shared by his research partners. A speech analysis was held in a group of units out of the original texts, which were applied to the Brazilian education reality. Such study allowed to verify the existence of a considerable distance between school teachers practices and those related to the academy knowledge, showing a gap between the school knowledge and the practices adopted in the teachers formation courses. One of the consequences of such problem is the massive presence, in the school routine, of more instructive aspects rather than educational. This may be proved by the identification of disciplinary and didactics aspects, where the methodological strategies are almost always confused with the textual formation of the mathematical knowledge.

Keywords: Teachers formation. School practices. Mathematics Education. 


\section{Tendências e desafios atuais}

Um dos desafios atuais para expandir as bases da formação de professores para a Educação Básica é superar a distância existente entre as práticas vivenciadas pelos estudantes de cursos de licenciatura e as práticas docentes a serem implementadas no campo da educação escolar. Entre essas duas instituições, Universidade e Escola, estão as práticas conduzidas pelos professores universitários responsáveis pela condução da formação dos futuros professores. Temos uma sensação, nada confortável, do ponto de vista educacional e político, de que existe uma nuvem camuflando a necessidade de debater a questão: articular as práticas conduzidas por quatro personagens: aluno da educação básica, estudante de licenciatura, professor da educação básica e professor universitário, sempre pensando em termos da especificidade da atividade matemática.

Houve apenas um avanço tímido nas últimas décadas para superar, do ponto de vista profissional, a distância existente entre essas práticas. Questão esta que coloca em destaque as relações entre as instituições formadoras e as práticas produzidas pelos professores que atuam na educação básica. Para tratar desta questão, recorremos à teoria antropológica do didático, proposta por Chevallard (1998), e, mais especificamente, ao conceito de transposição didática, visando interpretar relações existentes na rede de instituições na qual as práticas de estudo da Matemática são cultivadas.

Ao questionar a relação existente entre as referidas práticas, podemos destacar duas posições radicais cujas implicações são, igualmente desastrosas, quando se pretende ampliar as bases de formação de professores. Uma delas consiste em não considerar, no contexto dos cursos de licenciatura, a natureza das práticas escolares, como se a produção dos professores e alunos da Educação Básica fosse algo distante da Universidade. $\mathrm{Na}$ outra posição extrema, ameaça uma concepção igualmente redutora de que a formação inicial ministrada nos cursos de licenciatura poderia reproduzir as práticas escolares, por vezes, circunscrita ao domínio de conteúdos específicos. Nosso desafio é contribuir para a superação dessas duas vertentes que não atingem a dimensão profissional de uma carreira docente comprometida com a produção escolar.

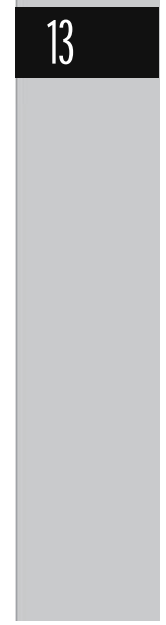


Por esse motivo, no campo da formação profissional universitária somos levados a destacar a especificidade do trabalho do professor, pois não devemos perder de vista a natureza do ofício docente. Não se trata de acentuar uma formação técnica e prática em detrimento da formação tecnológica e teórica, pois todo saber fazer está ligado a um saber, usando aqui uma das ideias defendidas por Chevallard (1998). Um dos maiores desafios consiste em questionar quais são as efetivas práticas pertinentes aos estudos ministradas pelas escolas. Nesse sentido, cabe uma ressalva, pois, muitas vezes, falamos apenas de práticas escolares, mas isso não significa redução ao domínio empírico, pois toda prática está permeada de um respectivo saber. No caso da formação docente, valorizar a articulação entre esses dois pólos das organizações didáticas é ainda mais do que necessário.

A reunião entre um saber disciplinar e o seu respectivo saber fazer forma o conceito de praxeologia produzida para resolver certos tipos de tarefa. Ao resolver certas tarefas de um determinado tipo, no contexto de uma instituição, as pessoas são levadas a construírem técnicas que possam ser justificadas, descritas e explicadas com base em tecnologias inseridas no quadro de uma teoria. Ao considerar o caso das tarefas escolares, esses quatro elementos praxeológicos - tipo de tarefa, técnica, tecnologia e teoria devem ser analisados do ponto de vista didático e matemático. Entretanto, não podemos confundir a natureza das tarefas docentes com aquela das tarefas discentes. Em outros termos, a compreensão docente de uma justificativa teórica quanto à validade de uma técnica não pode ser confundida com a explicação fornecida por um aluno.

Essa questão nos leva a reconhecer a existência de uma distância considerável entre as práticas acadêmicas, normalmente vivenciadas nos cursos de licenciatura, e as práticas pertencentes à educação escolar básica. Segundo nosso entendimento, as razões dessa distância não estão circunscritas aos aspectos didáticos ou epistemológicos, mas sim o contrário, pensamos que têm profundas raízes políticas e estão vinculadas ao compromisso social das instituições envolvidas. Por esse motivo, é preciso explicitar a posição na qual nos colocamos para defender um avanço em relação às propostas dos modelos mais tradicionais de formação. O campo geral de reflexão, onde as diferentes posições são assumidas, é formado pelas tendências atuais das pesquisas educacionais. 
No campo da Educação Matemática convivem diferentes linhas de pensamento e cada qual aborda certas dimensões da atividade escolar. Algumas estão mais voltadas para o domínio de conteúdos, como se o saber matemático não tivesse relação com as práticas sociais; enquanto outras vertentes destacam a dimensão cultural ou social da atividade matemática. Dessa maneira, tendo em vista a diversidade do fenômeno educativo, não há convergência absoluta no tratamento das questões do ensino de uma disciplina. Dentro de cada área específica das disciplinas escolares convivem diferentes posições teóricas e metodológicas. As categorias e métodos escolhidos esboçam uma solução cuja validade depende das posições assumidas.

A superação da distância entre as práticas vivenciadas pelos alunos nos estudos universitários e as práticas docentes próprias para a condução dos estudos escolares, no caso da Educação Matemática, passa pela presença marcante das raízes positivistas da disciplina de referência. Ocorre certa confusão entre a dimensão cartesiana e positiva dos saberes disciplinares e as organizações didáticas propostas na condução do estudo. Em outros termos, os problemas didáticos e o da formação docente não têm uma solução única e as raízes epistemológicas devem ser consideradas em cada caso.

A evolução possível não ocorre dessa maneira em vista da diversidade e da natureza do fenômeno cognitivo. A expansão da Educação Matemática, nas últimas décadas, revela avanços que não devem ser esquecidos. $\mathrm{O}$ aumento do número dos cursos de pós-graduação redimensionou o panorama existente na década de 1980. A facilidade de acesso aos textos especializados, como acontece hoje, praticamente não existia até pouco tempo. Essa facilidade expande as condições para levantar dados de pesquisa e também motivar a concepção de novas práticas.

O número de congressos específicos da área de Educação Matemática aumentou de forma considerável nas últimas décadas. As publicações representativas dos diferentes programas de pesquisa são também cada vez mais acessíveis. Assim, ficam ampliadas as possibilidades de repensar concepções e práticas. Livros didáticos atuais trazem aspectos inovadores quanto às organizações didáticas, aos recursos de ensino e sugerem estratégias diferenciadas. Esse tipo de material apenas induz a escolha das praxeologias a serem adotadas, mas trata-se, em sua maioria,

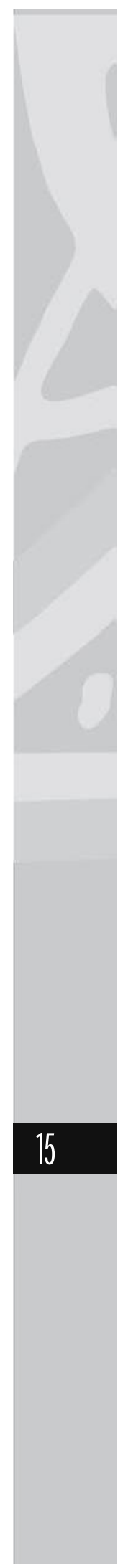


de uma considerável fonte de referência da prática docente porque sintetiza resultados de várias frentes de pesquisas desenvolvidas nas últimas décadas.

Nos últimos anos, tem ocorrido um aumento expressivo das fontes de referências curriculares, pedagógicas e didáticas. No entanto, as influências na formação docente ainda são tímidas, porque esse aumento permanece ainda mais no plano do saber a ser ensinado, e a penetração no saber acadêmico e no saber ensinado não ocorre de forma significativa. A maioria dessas fontes resultou do trabalho integrado de educadores, pesquisadores e do poder público, mas não envolve toda a rede de instituições na qual a educação escolar está inserida. Diante desse quadro, somos levados a indagar pelas implicações desse vasto material na prática docente, na realidade da sala de aula, nas distantes escolas públicas, nos rincões mais pobres, nas periferias das grandes cidades e nas condições de melhoria da educação pública. Há uma distância entre a potencialidade dessas fontes e a realidade educacional. O peso social dessa distância não pode ser minimizado pelos educadores. Assim, somos levados a falar também de alguns desafios e obstáculos existentes nesse movimento.

Um dos desafios consiste ainda em desenvolver práticas que possam contribuir na formação docente, quer seja nos cursos de pedagogia ou nas licenciaturas específicas, bem como nos primeiros anos de experiência no magistério. Embora os formadores dos futuros professores tendam a focalizar essa análise para as práticas externas ao domínio universitário, nossa experiência tem revelado a necessidade de repensar essa tendência porque o poder de influência exercido pelas práticas e pelos saberes acadêmicos é muito mais intenso do que se pode imaginar.

Quando trabalhamos com as disciplinas de Didática ou de Prática de Ensino, temos a oportunidade de perceber, com mais clareza, esse tipo de influência na formação dos futuros professores. Em muitos casos, as técnicas matemáticas estudadas nas disciplinas dos cursos de licenciatura nem sempre são adequadas para tratar das tarefas pertinentes ao efetivo trabalho docente. As praxeologias associadas ao saber acadêmico, sobretudo, aquelas da vertente clássica de formação, não têm raízes nas atividades conduzidas pelos futuros professores. Por trás desse desafio, há uma atitude conservadora, em termos de compromisso político, como se os problemas escolares pudessem ser distanciados das práticas 
da formação. A solução para mudar esse quadro é zelar para que todas as forças convergentes possam ser somadas para ampliar as atuais condições de racionalização das práticas formadoras, aproximando o trabalho docente da natureza real das praxeologias pertinentes.

Como consequência desse problema da formação surge um segundo desafio relacionado à função didática das atuais fontes de influências da prática docente, como os PCN e as regras instituídas pelo PNLD, entre outras. A formação inicial é o momento ideal para também principiar a compreensão do significado dessas fontes e da maneira de articular as suas orientações com a prática. Essa discussão toma corpo na medida em que os formadores se engajam de corpo e alma nessa missão, rompendo com a persistente separação entre conteúdos específicos e disciplinas pedagógicas. Em outros termos, trata-se de considerar os resultados já produzidos nessas últimas décadas e as experiências bem sucedidas. É preciso superar qualquer mal entendido quanto à finalidade das fontes orientadoras da prática que não é padronizar as ações didáticas, mas mostrar estratégias representativas para explorar a potencialidade educativa da Matemática. Em vista da influência dessas fontes, existem algumas noções didáticas relativas ao ensino da Matemática que revelam traços de uma prática docente idealizada. Um desafio a ser vencido na passagem dessa idealização para a prática é tratar a questão a partir das realidades institucionais envolvidas.

Quando defendemos a necessidade de envolver diferentes instituições da rede existente no entorno da escola, não podemos desconsiderar a presença marcante da visão clássica no ensino da disciplina. A prática usual inspirada nessa visão caracteriza-se por atividades concebidas e implementadas, quase somente, em torno dos conteúdos conceituais. Falar em conteúdos procedimentais ou atitudinais é algo estranho aos defensores dessa vertente tradicional do ensino da Matemática, porque todas as ações e valores praticados por eles estão voltados para os conceitos matemáticos. Segundo nosso ponto de vista, essa concepção de educação ainda exerce uma influência considerável na condução da prática e nos fundamentos da formação de professores.

A tendência clássica presente nos programas de formação fundamenta-se no pensamento euclidiano, cujo pressuposto central consiste em valorizar a sistematização do saber matemático através da 
lógica dedutiva. Trata-se da uma inversão do fluxo histórico no qual os conhecimentos foram elaborados. De acordo com Gascón (2003), podemos tratar da visão clássica como uma linha de atuação onde as praxeologias são concebidas com base nesse tipo de pensamento. De acordo com a interpretação feita por este pesquisador, a visão clássica é conduzida pela articulação de outros dois tipos de organizações didáticas que são os referenciais tecnológico-teórico e tecnicista.

Trata-se de um tipo de prática onde há uma reduzida valorização da dimensão exploratória da atividade matemática. O aluno não é levado a interagir mais diretamente com a atividade matemática, em busca de uma técnica ou do esboço de uma técnica para realizar um tipo de tarefa. O traço mais relevante dessa vertente positivista é ainda a precedência dos conteúdos, métodos e objetivos desenvolvidos no território interno do saber matemático, entretanto, não podemos deixar de conceber que este saber é apenas um dos pólos da transposição didática e qualquer radicalização tende a minimizar o significado dos saberes escolares. Por exemplo, mesmo que a noção de contextualização do saber escolar esteja presente entre os traços da vulgata contemporânea, não podemos desconsiderar a existência da vertente clássica, onde o contexto de ensino está, quase sempre, circunscrito ao próprio saber matemático.

De modo geral, há sinais de mudanças no cenário mais amplo da Educação Matemática, como mostram alguns livros didáticos atuais, onde os conteúdos são usados como instrumento para resolver problemas, ao invés de serem tratados apenas como objeto de estudo. Propostas construtivistas originadas a partir do movimento da Escola Nova, no que diz respeito à valorização da dimensão experimental, estão presentes em muitas das estratégias atuais de ensino da Matemática. Mas, por outro lado, sabemos que as propostas construtivistas foram, no Brasil, implementadas mais facilmente em nível das séries iniciais, tendo em vista as condições específicas da faixa etária envolvida e da menor matematização das práticas didáticas.

A título de exemplo, destacamos a liderança exercida pelo educador matemático brasileiro Euclides Roxo, na década de 1930, conforme analisa Valente (2002), quando aconteceu em um momento de particular crescimento da influência das ideias do movimento da Escola Nova no ensino da Matemática. Mas, quando analisamos as práticas predominantes 
no Ensino Médio, por exemplo, percebemos que a visão construtivista não tem a mesma presença que tem nas séries iniciais. Por outro lado, a partir da influência do movimento tecnicista, predominante na década de 1970, ainda existem traços atuais dessa vertente pedagógica calcada na valorização do uso irrefletido do automatismo, da cópia e da repetição como estratégias de ensino, em detrimento das ações e dos argumentos que justificam a validade dos modelos e das regras presentes no estudo da Matemática. Traços dessa prática de cunho tecnicista, de maneira geral, podem ser ainda identificados nos diferentes níveis da educação Matemática escolar.

\section{Além das práticas docentes reflexivas}

Para analisar as relações de proximidade e distância entre práticas docentes escolares e práticas universitárias, é preciso, cada vez mais, valorizar as bases das chamadas práticas docentes reflexivas, uma das linhas atuais de discussão da formação profissional e em particular de professores. Como mostra a literatura pertinente, alguns autores que propuseram ideias em torno das práticas reflexivas não estavam pensando somente no caso da formação docente, tinham a intenção de pensar em termos da formação do profissional reflexivo, como uma das exigências da atual sociedade da informação e dos desafios da globalização econômica.

Ao considerar os princípios contidos nas propostas de formação reflexiva, diante da inserção crescente dos recursos tecnológicos nas práticas escolares, nos resta ainda o desafio de ampliar as condições de profissionalização da carreira docente. Não podemos perder de vista a dimensão histórica do problema educacional, pois a abertura de cursos universitários para formar professores é relativamente recente, ao compararmos com os primeiros cursos superiores para formar médicos, advogados, militares e engenheiros. Somente a partir das primeiras décadas do século $\mathrm{XX}$, surgem projetos mais duradouros de cursos para formar professores, o que ocorre não somente no Brasil como em diversos outros países. Portanto, ao pontuar a formação reflexiva, três níveis se destacam em torno da questão: formar profissionais reflexivos; formar educadores reflexivos e, finalmente, formar professores reflexivos para ensinar Matemática.

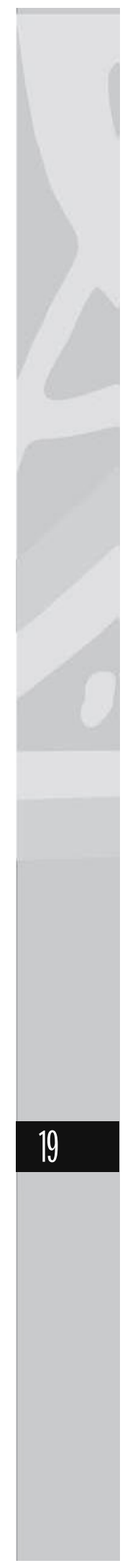


Há uma diferença considerável entre um engenheiro que ensina Matemática para alunos da educação básica, um professor licenciado que somente visualiza os conteúdos matemáticos em detrimento da dimensão humana da cognição e um educador reflexivo que conduz a realização de atividades matemáticas, visando uma formação integral para a cidadania. A direção é considerar a especificidade educativa do estudo da matemática escolar, sem perder de vista suas conexões com os demais saberes presentes na rede de instituições na qual a escola está inserida.

A resolução de uma questão matemática pontual estudada no Ensino Médio, por exemplo, pode envolver uma composição sucessiva de técnicas cuja compreensão inicial pode ter raízes nos conteúdos das séries iniciais. A quebra dessa rede encadeada de técnicas pode bloquear o estudo da Matemática. Assim, ao falar de práticas reflexivas na Educação Matemática, devemos, inicialmente, considerar os resultados já sintetizados pelos pesquisadores que estudam a formação profissional e indagar como funcionaria essa prática no ensino da Matemática. É preciso estabelecer, além do diálogo interno à área, outra linha de comunicação com os desafios da formação do profissional reflexivo. Ao destacar esse aspecto, nossa intenção é contribuir na identificação das fronteiras comuns entre a Educação Matemática, os fundamentos mais amplos da Educação, sem perder de vista a especificidade do saber matemático, bem como das ciências humanas de referência.

Para analisar as condições de expansão das práticas reflexivas na Educação Matemática, precisamos indagar sobre o que pretendemos refletir, deixando claro qual é o objeto dessa reflexão. Em seguida, somos levados a estudar de que maneira essa reflexão pode ser realizada, ou seja, como o professor pode conduzir essa prática, sem perder de vista o poder das instituições envolvidas. Temos também a tarefa de compreender os motivos e os valores que sustentam essa reflexão e ainda o momento certo de exercê-la.

Em decorrência dessas questões interligadas, retornamos às diversas tendências atuais da Educação Matemática, onde podem surgir soluções nem sempre concordantes. Por exemplo, podemos dizer que não existe reflexão alguma em uma prática docente conduzida somente pelos conteúdos matemáticos? Por esse motivo defendemos a necessidade de se ter uma linha metodológica relativamente estabilizada e, a partir dos 
valores envolvidos nessa posição, defender, com mais clareza, uma prática docente reflexiva. Mas, essa questão deve ser tratada desde a formação inicial e não poderia estar reduzida a uma única linha paradigmática centralizada em torno da Matemática.

Nossa intenção é fazer algumas articulações entre questões mais amplas da formação e da prática docente com a especificidade da Educação Matemática. Esse é um diálogo possível e necessário para ampliar a dimensão profissional do trabalho docente, de maneira geral, e em particular do professor de Matemática. Além de pensar nos desafios da aproximação mútua da pesquisa com a prática de ensino, estamos também interessados em considerar os problemas já levantados no campo pedagógico mais amplo da formação de professores, tal como a necessidade de expandir a dimensão profissional das práticas docentes. A nossa intenção é considerar a especificidade do trabalho docente no ensino de Matemática e não perder de vista os desafios comuns a todas as disciplinas.

Todo esforço deve ser empreendido para aproximar tudo o que possa ser aproximado para superar os prejuízos acumulados e incorporar as sínteses que foram produzidas. Dois aspectos podem ser destacados na análise dessa questão. De um lado, parte dos formadores cultiva práticas conduzidas somente pelos conteúdos e a contextualização fica restrita ao território científico. Do outro lado, temos o desafio da formação nos cursos de Pedagogia, onde predomina, muitas vezes, uma insuficiência do tratamento conceitual dos conteúdos específicos. Nossa atuação como professor dos cursos de Pedagogia e de Matemática tem nos proporcionado a oportunidade de tecer algumas comparações entre esses dois níveis de especificidade da Educação Básica.

Os elementos epistemológicos da atividade escolar estão articulados a outro conjunto de elementos didáticos, constituído por objetivos, valores, métodos, estratégias de avaliação e dispositivos didáticos. Assim, não é suficiente saber como funciona um algoritmo. Além do domínio de conteúdo, o trabalho docente leva-nos a refletir sobre como irá funcionar o entrelaçamento entre as organizações matemáticas e didáticas, lembrando que não há neutralidade no saber científico. Segundo nosso ponto de vista, essa é a essência educacional da questão metodológica. $\mathrm{O}$ ensino tradicional faz opção por uma visão na qual predomina a parte estática 
das praxeologias matemáticas, sem considerar os valores que podem ser associados à utilização do saber científico.

\section{Prática docente e diversificação de recursos}

Diferentes recursos das tecnologias digitais estão cada vez mais disponíveis para o uso escolar e provocam a nossa imaginação para identificar, ou pelo menos esboçar, o estatuto a ser construído pelos educadores para o uso didático desses equipamentos. Se na parte administrativa os computadores estão auxiliando o controle da vida escolar, no plano didático, a discussão está apenas começando. Nosso interesse é compreender as possíveis alterações na parte mais específica do estudo da Matemática e também na prática docente, sobretudo, nas estratégias de organização da prática e na formulação de técnicas compatíveis com a potencialidade do recurso utilizado. Para abordar esse tema, descrevemos, nos próximos parágrafos, um exemplo relativo ao estudo da geometria.

Um dos aspectos associados ao uso dos computadores no ensino da Matemática e capaz de provocar uma reflexão quantoàs possíveis alterações na condução da prática, em termos dos objetos ostensivos utilizados, diz respeito à diversificação dos recursos visuais de comunicação. A princípio, essa ampliação envolve todas as disciplinas, mas podemos indagar a respeito das possíveis diferenças no caso do ensino da Matemática. Em uma pesquisa recente analisamos o caso de livros didáticos que mostram uma expansão do uso de recursos visuais de comunicação por meio de desenhos, fotos coloridas, perspectivas e esquemas gráficos, entre outros, associados ao estudo dos sólidos geométricos. Trata-se de dispositivos usados para ampliar o componente visual da tarefa a ser realizada pelo aluno e pelo professor.

Se por um lado esse aspecto envolve outras disciplinas, por outro, tais recursos redimensionam variáveis próprias do estudo da geometria, tal como a inserção de recursos diferenciados para representar um sólido geométrico por meio de uma figura plana. Mais especificamente, o uso das cores para incrementar as técnicas do desenho em perspectiva, pela qual fica ressaltada a terceira dimensão do conceito representado. Dessa maneira, essa diversificação de recursos visuais não é apenas a inovação de mais um dispositivo, como se fosse algo sem maiores novidades. Pelo 
contrário, se o uso desse recurso não altera a dimensão não-ostensiva do saber envolvido, provoca alterações potenciais nas técnicas e nos instrumentos de estudo.

Destacar a terceira dimensão de um sólido geométrico através de uma perspectiva é uma técnica fundamental para ampliar os tipos de tarefas estudadas no contexto escolar. Mas, com a incorporação do uso das tecnologias digitais, essa técnica está sendo ampliada por outras mais inovadoras, por exemplo, utilizando diferentes tonalidades ou reflexos para ressaltar a terceira dimensão do objeto. Há um suporte tecnológico diferenciado dos anteriores para diversificar a linguagem utilizada no estudo escolar. Esses aspectos mostram uma convergência na caracterização dos livros didáticos atuais, mas, por outro lado, revelam também uma possível tendência de padronização dos recursos sugeridos. Entretanto, no plano da formação docente, somos levados a refletir sobre os aspectos positivos dessa tendência, mas também pelos seus possíveis limites, no sentido de não pretender nenhuma padronização imperativa das práticas. Por certo, essa questão motiva-nos a estruturar novos objetos de pesquisa para melhor compreender o atual processo de textualização do saber escolar e das práticas docentes.

\section{Relação entre Matemática e Didática}

A abordagem antropológica proposta por Chevallard (1998) defende o princípio da articulação integrada entre organizações matemáticas e didáticas. Cada praxeologia é formada por tipos de tarefas, técnicas, tecnologias e teorias e cada um desses elementos tem, ao mesmo tempo, natureza matemática e didática. O conhecimento matemático resulta da atividade de estudo e o objeto da didática é esse processo de estudo. A elaboração do conhecimento depende do envolvimento das pessoas e das instituições em um efetivo processo de estudo. Assim, o ensino é concebido como um recurso para o estudo e a aprendizagem uma consequência das ações vivenciadas pelo estudante. A noção de praxeologia sintetiza esses dois aspectos integrados da atividade matemática. Portanto, ao estudar as práticas docentes, somos levados a pensar em outra maneira de conceber as relações entre os conteúdos matemáticos e as disciplinas pedagógicas. 
Como não existe uma separação absoluta entre os aspectos didáticos e matemáticos, não faz sentido conceber as disciplinas específicas de forma isolada dos aspectos didáticos, da mesma maneira como também não faz sentido idealizar as disciplinas pedagógicas desprovidas de vínculos com as raízes epistemológicas da Matemática. Esse é um ponto nevrálgico de grande parte das atuais práticas de formação que insistem na vertente da separação, ao invés de lançar articulações em busca da expansão do significado.

Nesse sentido, a superação do modelo tradicional de formação, no qual os aspectos didáticos são, quase sempre, tratados de maneira separada dos aspectos matemáticos, passa pelo viés da prática reflexiva no sentido amplo do termo, isto é, incluindo aí as práticas dos formadores de professores. A realização dessa prática é possível a partir do estudo integrado dos diferentes fundamentos da atividade matemática: epistemológicos, antropológicos, didáticos, históricos, entre outros, além da própria dimensão científica.

D'Amore (2004), seguindo a vertente antropológica, destaca a necessidade de ampliar a reflexão em torno da formação de professores, quanto à valorização dos fundamentos da Matemática. De modo geral, esse tipo de conhecimento não é estudado na formação inicial, talvez, com exceção da História da Matemática, muitas vezes, estudada somente de forma centralizada em torno do território conceitual. Em suma, a especificidade do trabalho docente relativo ao saber matemático, ainda não é suficientemente analisada do ponto de vista de seus fundamentos. Além de expandir a compreensão do saber matemático na direção conceitual, o estudo de aspectos epistemológicos pode proporcionar, ao professor, uma linha de reflexão, resgatando a localização da atividade matemática nos quadros institucionais que lhes deram origem.

\section{Aspectos praxeológicos da prática docente}

Os estudos feitos na esteira do programa epistemológico, desenvolvido a partir dos trabalhos de Guy Brousseau, iniciados na década de 1970, destacam a importância de se valorizar uma dimensão fundamental da prática docente que é a natureza da atividade matemática. Assim, se o objetivo de uma pesquisa é desvelar um fenômeno didático relacionado 
ao estudo da Matemática, a partir de uma teoria vinculada ao Programa Epistemológico, a consciência do pesquisador deve estar voltada para os elementos da atividade matemática, sem esquecer o peso considerável da especificidade resultante das instituições envolvidas.

Para aplicar esse postulado é preciso indagar a propósito da maneira como a atividade matemática é normalmente desenvolvida no contexto institucional no qual a prática está inserida, procurando identificar os aspectos mais valorizados, o grau de refino da dimensão teórica, o tratamento dado ao processo de argumentação e assim por diante. Em uma instituição especializada na preparação dos alunos que irão fazer o vestibular de uma concorrida Escola de Engenharia, o peso atribuído aos conteúdos matemáticos e a própria natureza dos problemas estudados são diferenciados. O tipo de prova adotado no vestibular dessa instituição funciona como fonte de influência na definição das práticas docentes. Entre todos os tipos de tarefas existentes no universo mais amplo do saber matemático, em função das referências institucionais, são escolhidos alguns que passam a ser mais valorizados no contexto das praxeologias adotadas.

Essas escolhas acontecem também em relação às técnicas, às tecnologias e às teorias associadas. Dessa maneira, em vista da realidade institucional, as práticas docentes são concebidas e implementadas em sintonia com esse quadro praxeológico no qual o professor está inserido. Esse vínculo entre os componentes da praxeologia matemática e a prática docente aparece também em outras noções mais amplas da abordagem antropológica como é o caso do gênero de tarefa que aparece na concepção do currículo em espiral, quando um mesmo tipo de problema volta a ser estudado, nos anos subsequentes, com maior grau de abrangência. Por isso, a realização de uma prática reflexiva requer uma percepção dessa expansão crescente das tarefas.

\section{Matematização do estudo}

A partir de uma análise didática dos saberes matemáticos, sem perder de vista as referências antropológicas do saber, o professor pode minimizar os efeitos não desejáveis da matematização do estudo, conforme observa Chevallard (1998). Para realizar uma prática reflexiva crítica é preciso 
identificar um problema persistente na vertente clássica que, segundo nosso entendimento, é a identificação metodológica entre a maneira de organizar o texto matemático e conduzir as estratégias de estudo. Em um estudo recente, destacamos que entre os autores do início do século XX, interessados pela questão metodológica da Matemática, estava Júlio Rey Pastor (1888-1962) que na sua obra Metodologia de la Matemática, publicada em 1926, chama a atenção para o que teria sido o principal equívoco da vertente tradicional: confundir as estratégias de ensino com as condições exigidas na sistematização final do texto matemático.

Existe neste ponto uma verdadeira nebulosa epistemológica, uma nuvem na qual se perdem as estratégias tradicionais, e os resultados dessa identificação são desastrosos. Mais especificamente, trata-se de adotar o método lógico-dedutivo, tal como é valorizado na sistematização do saber. A degeneração dessa vertente recai no formalismo, quando a sistematização é considerada como o objetivo mais importante do ensino. Considerando a abordagem antropológica, incluímos entre os elementos da matematização do estudo essa identificação entre a forma de redigir o texto matemático e as estratégias de condução do ensino.

\section{Níveis do saber matemático}

Para explicitar relações entre uma tarefa matemática particular e práticas sociais mais amplas, Chevallard (1998) destaca nove níveis de determinação do saber, cuja análise amplia as bases teóricas e práticas da formação docente. Esses níveis são os seguintes: civilização, sociedade, escolar, pedagógico, disciplinar, domínio, setor, tema e questão, os quais devem ser analisados em relação a um contexto institucional preciso, pois esboçam praxeologias interligadas por meio das quais podemos fazer uma leitura dos estudos escolares. Por exemplo, o nível disciplinar da matemática dos anos finais do Ensino Fundamental é constituído pelos domínios: geométrico, aritmético, algébrico, medidas, probabilístico, combinatório e estatístico. Cada um desses domínios pode ser subdividido em setores de estudo, os quais são compostos por temas e estes, por sua vez, podem ser formados por questões de estudo.

Com base na leitura das referências, interpretamos que um grau mais refinado de análise praxeológica pode ser estabelecido, ao dividirmos 
uma questão de estudo em diferentes tipos de tarefa, sendo que cada um destes, por sua vez, será composto por um grande número de tarefas. No sexto ano do ensino fundamental, em certas instituições, determinar a geratriz da dízima 0,44444 ... é uma tarefa pertencente ao seguinte tipo de tarefa: determinar a geratriz de uma dízima periódica simples cujo período é formado por um algarismo. Se reunirmos este tipo de tarefa com outros tipos, nos quais os períodos são compostos por mais de um algarismo, temos então a questão de estudo: determinar a geratriz de uma dízima periódica. Mas, o estudo das dízimas não se reduz, pelo menos nas instituições por nós idealizadas, às tarefas de encontrar a geratriz, ou seja, envolve outras questões tais como verificar se uma dada fração resulta ou não em dízima, ou ainda questões mais conceituais como identificar os motivos pelos quais uma fração resulta em dízima, ao ter seu numerador dividido pelo denominador. As dízimas periódicas acrescidas de outros temas formam o setor de estudo números racionais, o qual juntamente com outros setores formam o domínio aritmético, uma das grandes divisões da disciplina de matemática dos anos finais do ensino fundamental.

O estudo das relações entre esses níveis epistemológicos e didáticos fornece uma estratégia de análise das práticas docentes, além de permitir uma ampliação crescente de abrangência do saber matemático desde as tarefas pontuais de um nível de escolaridade até nos níveis mais amplos da sociedade ou de uma civilização. A pontualidade de uma questão escolar vai sendo ampliada para envolver, pouco a pouco, níveis mais amplos do saber matemático. Entretanto, de modo geral, o nível disciplinar tende a ficar restrito ao espaço escolar, em vista de uma cultura produzida no território da instituição. Esta talvez seja uma linha de fronteira que aproxima e separa a visão antropológica proposta por Chevallard (1998) e a noção cultural escolar, na linha proposta por Chervel (1990).

O conceito de vulgata, proposto por esse autor, sintetiza o que existe de comum, em um dado momento, em torno das práticas usuais de uma disciplina escolar, sendo formada por conteúdos, objetivos, métodos e problemas típicos que predominam como os elementos condutores da prática docente. Uma parte da vulgata característica de um período aparece nos livros didáticos, fazendo com que, em dado momento, essas publicações apresentem certa semelhança entre si. De maneira geral, existem diferenças entre os livros didáticos, mas nem 
sempre são facilmente perceptíveis em uma leitura rápida. Segundo nosso entendimento, há uma proximidade entre o viés proposto por Chevallard (1991), ao descrever o conceito de textualização do saber a ser ensinado e a valorização cultural dos livros didáticos como expressão publicada da vulgata.

A escolha de conteúdos, métodos e recursos resultam das fontes de influência que atuam na transposição didática e tais elementos encontramse registrados em relatórios, teses, artigos, softwares, parâmetros curriculares, programas, nos exames e em outras fontes como os livros didáticos. São registros publicados para defender a validade do saber a ser ensinado e delinear a forma como eles devem ser conduzidos pelo professor. Entre os registros textuais do saber escolar, temos escolhido o livro didático para servir como fonte de dados de pesquisa. Um dos argumentos para justificar essa escolha decorre da influência que esse dispositivo normalmente exerce na condução da prática, como fonte de referência e de validação do saber a ser ensinado.

Os momentos de estudo se caracterizam pelos tipos de tarefas propostos aos alunos e pela maneira como são conduzidos pelo professor, até mesmo quando se trata de apresentar um novo tipo de problema por meio de uma exposição oral. Nesse sentido, na análise da prática docente, através da abordagem antropológica, o pesquisador deve estar atento aos níveis de argumentação decorrentes da posição de cada um desses dois atores do processo de estudo. Quando pensamos em uma organização matemática, essas duas posições não devem ser confundidas porque isso reduziria a dimensão profissional do trabalho docente. Desse modo, um desafio é buscar uma visão integradora entre os níveis de atividade matemática escolar, onde nem sempre a matemática social é reconhecida como elemento capaz de contribuir na constituição do saber escolar.

$\mathrm{Na}$ totalidade dos estudos previstos em uma faixa específica da escolaridade, o professor deve estar atento às articulações possíveis entre esses níveis mais pontuais e as referências antropológicas mais amplas. Muitas vezes, na vertente da formação tradicional, predomina dois enfoques extremos. No quadro das disciplinas específicas, predomina o estudo de questões circunscritas ao nível disciplinar, sem mencionar a dimensão didática na qual o professor irá efetivamente atuar. Do outro lado, por ocasião do estudo da disciplina de didática, quase sempre, 
predominam questões pedagógicas, sem considerar a dimensão conceitual do saber matemático. A síntese a ser feita entre os aspectos didáticos e matemáticos é deixada por conta do futuro professor.

A possibilidade de ampliar as condições de diálogo entre a prática e a pesquisa passa também pela superação dessas duas posições radicais. Certamente, não há solução mágica para fazer avançar esse problema, mas uma das linhas de atuação é a construção de linhas de articulação entre as organizações didáticas e matemáticas, considerando os vínculos com as atividades humanas e sociais. Consiste em levar os professores a intervirem, com mais intensidade, nas questões pedagógicas, para modificar as condições de profissionalização da carreira docente. Mas, há uma dupla dificuldade a ser vencida que é a superação da crença de que a intervenção isolada ao nível do pedagógico possa determinar a parte essencial da prática docente, bem como a idéia igualmente redutora de que somente as referências oriundas do saber acadêmico possam determinar a natureza do trabalho do professor.

\section{Rumo a uma convergência}

O nível de determinação do saber pedagógico, em vista de sua generalidade, nem sempre contribui para ampliar, de modo significativo, as condições da prática de ensino da Matemática porque não atinge a especificidade das questões didáticas, no sentido atribuído pelo programa epistemológico. Isso não quer dizer que haja uma enorme distância entre as questões pedagógicas e didáticas, mas a confusão instituída entre esses dois níveis, por certo, foi responsável por uma parte dos prejuízos acumulados na vertente clássica da formação. Por esse motivo, entre as competências docentes está a necessária disponibilidade para compreender, de maneira articulada, as características comuns a todas as disciplinas e, por outro lado, o que pertence ao território da área específica. Mas, sabemos que esse diálogo entre generalidade e especificidade nem sempre foi fácil de ser conduzido nas práticas docentes e formação de professores.

Essa ligação entre a dimensão pedagógica e didática pode ser interpretada, segundo nosso entendimento, a partir da observação feita por Shulman (1992) quando destaca a noção de compreensão do saber como uma condição essencial para o exercício da docência. Ao destacar as 
ideias de Shulman (1986), Ponte (1999) relembra que uma das condições da atividade docente é a necessidade de se ter um profundo domínio conceitual na área de atuação. Porém, não se trata de confundir esse tipo de domínio com aquele que caracteriza o trabalho matemático. Talvez esse tenha sido um dos equívocos da vertente tradicional da formação, ao priorizar praxeologias nem sempre suficientes para o exercício da docência.

A partir das considerações descritas neste texto, cumpre-nos ressaltar a maneira como concebemos as relações entre as práticas docentes e práticas universitárias, sendo estas pertinentes aos cursos de licenciatura. $\mathrm{O}$ polimento da arte de ensinar se faz por meio de uma permanente expansão das articulações entre os conteúdos disciplinares e a sua correspondente dimensão didática. A especificidade do trabalho docente se faz pela confluência de duas outras especificidades: o disciplinar e o didático. Essa condição da especificidade do trabalho docente não pode ser confundida com a natureza própria do saber acadêmico, no sentido de evitar que os conteúdos possam ficar circunscritos a um território fechado em si mesmo e distante dos desafios próprios da educação escolar.

Finalmente, a compreensão das praxeologias docentes envolve, além do plano conceitual específico, diversos fundamentos pelos quais a proposta educativa pode ser realizada, envolvendo, entre outros, aspectos epistemológicos, históricos, psicológicos e antropológicos. Nesse sentido, um desafio pertinente à formação de professores consiste em analisar diferentes estratégias pelas quais o conhecimento matemático pode ser elaborado e não reduzir, no plano escolar, a atividade escolar aos trâmites burocráticos de uma formalização textual do saber. O saber docente inclui uma dimensão específica caracterizada por diferentes tipos de tarefas e estratégias pelas quais o aluno pode vivenciar um contato direto com as obras matemáticas.

\section{REFERÊNCIAS}

BRASIL. Ministério da Educação/Secretaria de Educação Fundamental. Parâmetros Curriculares Nacionais: matemática $-1^{\mathrm{o}}$ e $2^{\mathrm{o}}$ ciclos. $3^{\mathrm{a}}$ ed. Brasília: MEC/SEF, 2001.

CHERVEL, A. La Culture Scolaire. Paris: Editora Belin, 1990.

CHEVALLARD, Y. Analyse des pratiques enseignantes et didactique des 
mathematiques: a abordagem atnropologique. In : Atas da Universidade de Verão realizada na cidade Rochelle. Clermont-Ferrand: Editora do IREM, 1998.

CHEVALlARD, Y. La Transposition Didactique. Paris: La Pensée Sauvage, 1991.

CHEVALLARD, Y. Organiser l'étude Ecologie et Regulation. In: Atas da 11 ${ }^{\text {a }}$ Escola de Verão de Didática da Matemática. Paris: La Pensée Sauvage, 2002.

D'AMORE, B. El papel de la epistemología em la formación de professores de matemática de la escuela secundaria. Revista de la Sociedad Andaluza de Educación Matemática Thales. Sevilla: 2004. p. 413-434.

GASCÓN, J. La Necesidad de utilizar modelos en didáctica de las matemáticas. Revista Educação Matemática Pesquisa. São Paulo, 2003. p 11-37.

PASTOR, J. Metodología de la Matemática. Buenos Aires: Editorial Ibero, 1926.

PONTE, J. P. Didácticas específicas e construção do conhecimento profissional. In: TAVARES, J.; PEREIRA, A; PEDRO, A. P.; SÁ, H. A. (Eds.). Investigar e formar em educação. Actas do IV Congresso da SPCE. Porto, 1999. p. 59-72.

SHULMAN. L. S. Renewing the pedagogy of teacher education: The impact of subject-specific conceptions of teaching. Encontro Las Didacticas Específicas en la Formación Del Professarado. Santiago do Compostela, 1992.

VALENTE, W. A Elaboração de uma Nova Vulgata para a Modernização do Ensino da Matemática: aprendendo com a história da Educação Matemática no Brasil. Rio Claro: Bolema 17, 2002. 